\title{
Challenges on participation in a cooperative group of childhood renal tumors in Brasil
}

\author{
(D)Lucian S. Viana ${ }^{1}$ \\ (iD) Neimar de Paula Silva ${ }^{1}$ \\ (iD) Nathalie V. Balmant ${ }^{1}$ \\ (iD) Paulo A. Faria ${ }^{3}$ \\ (iD) Marceli O. Santos ${ }^{4}$ \\ (iD) Rejane S. Reis ${ }^{2}$ \\ (iD) Beatriz de Camargo'
}

1. Centro de Pesquisa, Programa de Pós Graduação, Instituto Nacional de Câncer, Rio de Janeiro, RJ, Brasil 2. Fundação do Câncer, Hospital Fundação do Câncer, Rio de Janeiro, RJ, Brasil 3. Departamento de Patologias (Dipat), Instituto Nacional de Câncer, Rio de Janeiro, RJ, Brasil 4. Coordenação de Vigilância e Prevenção, Instituto Nacional de Câncer, Rio de Janeiro, RJ, Brasil

http://dx.doi.org/10.1590/1806-9282.66.3.284

\section{SUMMARY}

OBJECTIVE: Children with renal tumors included in clinical trials have significantly better outcomes. In Brasil, the enrollment of patients in clinical trials remains challenging. Here we aimed to describe participation accrual in the Brazilian Wilms Tumor Study Group (BWTSG) and to identify barriers to trial registration of children with renal tumors.

METHODS: We determined the numbers of renal tumor diagnoses in 105 hospital-based cancer registries from 2001-2009. We then compared these totals with the numbers of renal tumor cases registered in the BWTSG from the same hospitals during the same time period. We also invited members of the Brazilian Pediatric Oncology Society to complete a 5-point Likert-type scale questionnaire regarding their opinions of the importance of participation in cooperative group trials.

RESULTS: The accrual rate of patient participation per hospital varied from $25 \%$ to $76 \%$, and was highest in the South region. The accrual rate of hospital participation also varied according to the region (20-31\%) and was highest in the Southeast region. For the questionnaire regarding the importance of participation in cooperative groups, the responses showed an agreement of $>75 \%$ on 10 of the 13 statements.

CONCLUSION: Our results demonstrated low accrual of participation in a cooperative group trial in Brasil. We identified variations in registration rates according to geographic region and hospital, which may help targeted efforts to increase registration rates. The survey responses demonstrated that colleagues understand the importance of trial participation.

KEYWORDS: Kidney neoplasms. Child. Neoplasms. Brasil.

\section{INTRODUCTION}

Centralized multidisciplinary treatment is the gold standard for childhood cancer. Pediatric clinical trials lead to increased survival rates and represent a unique resource for expanded investigations of the treatment, biology, and etiology of childhood cancer worldwide'. In particular, collaborative group trials have yielded significant therapeutic advances. For example, clinical trials for Wilms tumor treatment

DATE OF SUBMISSION: 16-Jul-2019

DATE OF ACCEPTANCE: 01-Sep-2019

CORRESPONDING AUTHOR: Beatriz de Camargo

Instituto Nacional de Câncer, INCA - Rua André Cavalcanti, 37, Rio de Janeiro, RJ, Brasil

Tel: +552132076535

E-mail: bdecamar@terra.com.br 
have supported increased cure rates and continued refinement of therapy ${ }^{2,3}$.

More complete registration of pediatric cancer patients in clinical trials improves outcome and quality of life and provides opportunities for translational research ${ }^{4}$. Cooperative group protocols for children undergoing cancer treatment have been widely available and successful around the world ${ }^{5-7}$. Uniform treatment facilitates the comparison of outcome data around the country. Importantly, identifying barriers to registration in cooperative groups can improve participant accrual rates and thus lead to improved survival.

In the present study, our aim was to describe participation accrual in the Brazilian Wilms Tumor Study Group (BWTSG) and to identify barriers to trial registration of children with renal tumors in Brasil.

\section{METHODS}

To assess the registration accrual of children with renal tumors in the BWTSG, we determined the number of renal tumor cases in each hospital-based cancer registry (HBCR) and compared these totals with the number of renal tumor cases registered in the BWTSG from each hospital during the same time period (20012009). Since 2001, the BWTSG has been merged with the SIOP-2001 study and has registered all cases in the SIOP-2001 database. HBCRs cover about $90 \%$ of the Brazilian public health system, comprising hospitals with oncological services located in the Federal District and 25 of Brasil's 26 states. We identified the HBCR dataset using the website Integrator System (http://www.inca.gov.br). Data were compiled into a single Excel database to compare the numbers of participating hospitals and cases registered in the BWTSG with the available HBCR information.

We additionally sought to assess our colleagues' opinions regarding the importance of participation in a cooperative group trial. To this end, 289 members of the Brazilian Pediatric Oncology Society (SOBOPE) were sent questionnaires that included 13 statements to rate using a 5-point Likert-type scale, where 1 indicated strongly agree, 2 agree, 3 neutral, 4 moderately disagree, and 5 completely disagree (Table 1 ).

\section{RESULTS}

A total of 1497 patients were diagnosed with childhood (0-14 years of age) renal tumors and registered in 105 HBCRs from 22 Brazilian states and the Federal District between 2001-2009. During the same period, 498 cases were enrolled in the BWTSG (Figure 1). Among the 105 HBCRs, 27 hospitals (26\%)

TABLE 1. STATEMENTS AND RESULTS OF THE LIKERT QUESTIONNAIRE

\begin{tabular}{|c|c|c|c|c|}
\hline Statement & $\begin{array}{l}\text { number of } \\
\text { participants }\end{array}$ & $\begin{array}{l}\text { median } \\
\text { score (IQR) }\end{array}$ & $\begin{array}{l}\% \text { of agree- } \\
\text { ment * }\end{array}$ & $\begin{array}{l}\text { Agreement } \\
\text { reached } \\
\text { reached }\end{array}$ \\
\hline $\begin{array}{l}\text { 1) To participate in a cooperative group it is necessary extra time on daily } \\
\text { activities. }\end{array}$ & 89 & $1(1-2)$ & 87,7 & yes \\
\hline 2) To participate in a cooperative group it is necessary financial support. & 89 & $3(3-4)$ & 39,3 & no \\
\hline $\begin{array}{l}\text { 3) Complete registry of all cases is essential to participate on a cooperative } \\
\text { group. }\end{array}$ & 89 & $1(1-1)$ & 98,9 & yes \\
\hline 4) The participation on a cooperative group is benefit to the institution. & 89 & $1(1-1)$ & 95,5 & yes \\
\hline 5) A task to participate is to obtain the inform consent from children/parents. & 89 & $4(4-5)$ & 28,1 & no \\
\hline $\begin{array}{l}\text { 6) To participate on a cooperative group is necessary a multidisciplinary team } \\
\text { participating to fill in the forms. }\end{array}$ & 89 & $2(2-2)$ & 92,1 & yes \\
\hline $\begin{array}{l}\text { 7) The participation in a cooperative group is important for treatment sucess } \\
\text { and overall survival of children with cancer. }\end{array}$ & 89 & $1(1-2)$ & 95,5 & yes \\
\hline 8) Health system improves with the participation on a cooperative group. & 89 & $1(1-2)$ & 96,6 & yes \\
\hline $\begin{array}{l}\text { 9) The major benefit to participate in a cooperative group is the scientific } \\
\text { contribution. }\end{array}$ & 89 & $2(2-2)$ & 87,6 & yes \\
\hline $\begin{array}{l}\text { 10) Extra time in filling the forms jeopardize the participation on a cooperative } \\
\text { group. }\end{array}$ & 89 & $2(2-4)$ & 69,6 & no \\
\hline 11) Despite the extra time it is worth to participate on a cooperative group. & 89 & $1(1-2)$ & 96,6 & yes \\
\hline $\begin{array}{l}\text { 12) To follow strictly the treatment protocol is essential to participate on a } \\
\text { cooperative group. }\end{array}$ & 89 & $1(1-2)$ & 97,7 & yes \\
\hline $\begin{array}{l}\text { 13) The participation on a cooperative group is benefit to all participants' } \\
\text { colleagues. }\end{array}$ & 89 & $1(1-2)$ & 93,2 & yes \\
\hline
\end{tabular}

*Agreement was defined as scores of 1 or 2 (1=strongly agree;2=agree, $3=$ neither agree or disagree, 4=disagree, $5=$ strongly disagree. 
participated in the BWTSG (Figure 2). Among these 27 hospitals, 834 renal tumor cases were registered in the HBCRs, and 389 renal tumor cases were registered in the BWTSG (47\%) (Table 2). Thirteen hospitals that participated in the BWTSG (with 109 cases) had no data available from HBCRs (Figure 1).

The accrual rate of patient participation per hospital varied from $25 \%$ to $76 \%$ and was higher in the South region. The accrual rate of hospital participation varied according to the region (20-31\%) and was highest in the Southeast region. Registration rates varied according to geographic region, with the accrual rate of patient participation per hospital being higher in the Northeast (67.4\%) and South (76.2\%) (Table 2).

Among the 289 SOBOPE members contacted, 89 (30\%) completed the Likert questionnaire. The answers revealed a greater than $75 \%$ consensus for 10 of the 13 statements in the questionnaire. The statement regarding the "need for financial support to participate" showed low agreement (39.3\%) and a median score of "neither agree nor disagree". Additionally, the "task of informed consent" had a median score of "disagreement". No agreement was achieved regarding the effect of the time needed to complete forms,

FIGURE 1. FLOW DIAGRAM OF PATIENTS INCLUDED IN HOSPITAL-BASED CANCER REGISTRIES (HBCRS) AND THE BRAZILIAN WILMS TUMOR STUDY GROUP (BWTSG) DURING THE PERIOD FROM 2001-2009

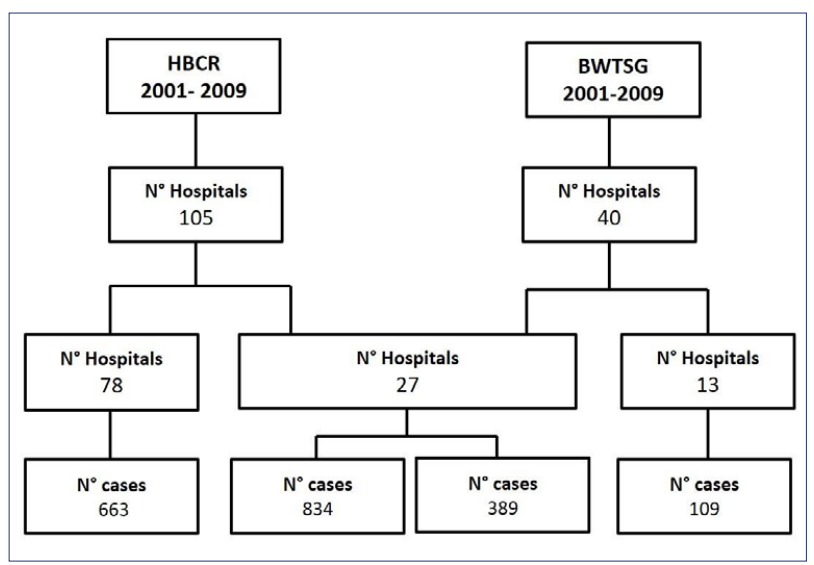

and the median response was "agreement". However, there was a high rate of agreement that participation was worth the extra time required (Table 1).

\section{DISCUSSION}

The goal of this study was to estimate the proportion of pediatric renal tumor patients in Brasil who were registered in the BWTSG. Our results indicated that compared with the numbers of renal tumor cases in HBCRs, substantially fewer patients were enrolled in the BWTSG.

Registration rates varied among geographic regions, which may reflect patterns of registration by physicians. Although the BWTSG aims to register all childhood renal cancer patients, the process relies on the physician providing information to the cooperative group data center, which requires knowledge and time. In Brasil, the BWTSG was created in 1986 and merged with the SIOP-2001 study in $2001^{6,8}$. The Brazilian Population-Based Cancer Registry (PBCR) is limited to capitals. In 13 Brazilian PBCRs, the median age-adjusted incidence rate of Wilms tumor was 9.5 per million, showing regional variations, with the lowest rate in Natal located in the Northeast region (5.2 per million) and the highest rate in Goiania in the Midwest region (18 per million) ${ }^{9}$. The estimated numbers of renal tumors in Brasil is around 600 new cases annually, and only $10 \%$ of children with renal tumors are registered in the BWTSG. During the first study of the Brazilian group, it was estimated that $25 \%$ of cases were registered ${ }^{10}$. One possible explanation for this difference may be that the first cooperative group trial guided the physicians to follow a treatment protocol and informed them of the necessity of registering in a study. Nowadays, Wilms tumor treatment is better known, and more oncology centers have been established throughout the country. The reduced imperative to join a trial, combined

TABLE 2. ACCRUAL RATES OF PATIENT AND HOSPITAL PARTICIPATION ACCORDING TO BRAZILIAN REGION

\begin{tabular}{|c|c|c|c|c|c|c|}
\hline \multirow[t]{2}{*}{ Brazilian geographic regions } & \multicolumn{2}{|c|}{$\mathrm{N}^{\circ}$ Hospitals } & \multirow{2}{*}{$\begin{array}{l}\text { Accrual rate } \\
\% \\
\end{array}$} & \multicolumn{2}{|c|}{$\mathrm{N}^{\circ}$ patients } & \multirow{2}{*}{$\begin{array}{l}\text { Accrual rate } \\
\%\end{array}$} \\
\hline & BWTSG & HBCR & & BWTSG & HBCR & \\
\hline North & 1 & 5 & 20.0 & 1 & 4 & 25.0 \\
\hline Northeast & 5 & 23 & 21.7 & 62 & 92 & 67.4 \\
\hline Midwest & 1 & 4 & 25.0 & 7 & 13 & 53.8 \\
\hline Southeast & 15 & 48 & 31.3 & 255 & 641 & 39.8 \\
\hline South & 5 & 25 & 20.0 & 64 & 84 & 76.2 \\
\hline BRASIL & 27 & 105 & 25.7 & 389 & 834 & 46.6 \\
\hline
\end{tabular}




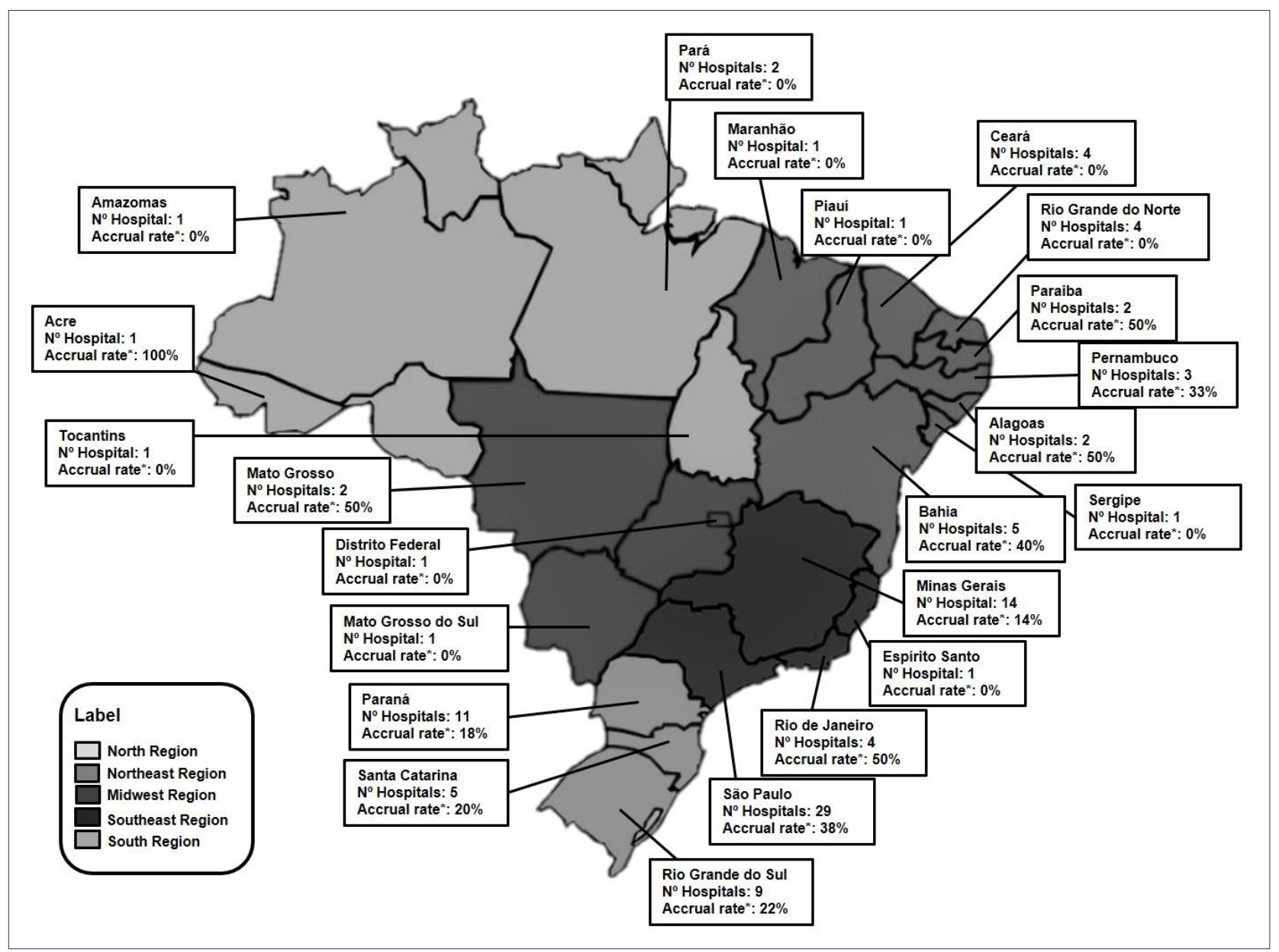

with the substantial time needed to participate in a study, are likely major factors reducing participation. However, with high cure rates, large numbers of patients are needed to demonstrate small incremental improvements, which can only be achieved through a cooperative group.

In our present study, we compared the numbers of cases registered in HBCR and BWTSG during the same period. We described the disparity between the numbers of renal tumors treated at the hospitals versus the enrollment of renal tumors in the BWTSG, and evaluated the representativeness of the registered renal tumors. Our results revealed variations among different geographic regions in Brasil. The accrual rate of cases registered in the BWTSG was highest in the South region, and the accrual rate of participating hospitals was highest in the Southeast. The North region had the lowest accrual rate of hospitals, as well as the second-lowest number of cases registered per hospital, exceeding only the Midwest region.
Pediatric clinical trial groups represent a unique resource to define the best treatment for pediatric cancers and to conduct clinical and biological research. Participation in cooperative groups improves survival, as well as facilitates the identification of possible associations and causes of childhood cancer ${ }^{1,5,11,12}$. Our present study documented the accrual rate of participation in the BWTSG and helped us identify hospitals that treat children with renal tumors and do not register all children. Despite the low accrual rate of participation, the BWTSG has been able to collaborate with the randomized SIOP-2001 study, bringing 126 randomized cases to this study to help answer important questions regarding the treatment of Wilms tumor ${ }^{8}$.

Participation in a cooperative group is considered the gold standard of treatment for childhood cancer. No single hospital has a sufficient number of patients to conduct a definitive, randomized, controlled trial. Participation in cooperative trials also has significant educational benefits with 
regards to the dissemination of standards of care, which extend across institutions and regions ${ }^{4}$. In the United States and Europe, 90-95\% of all children under age 15 with a newly diagnosed malignancy are treated within a cooperative group following a clinical trial protocol ${ }^{12,13}$. One successful example is the treatment of Wilms tumor through the creation of the National Wilms Tumor Group in 1969 in the United States. Five consecutive studies (1969-2002) demonstrate that multidisciplinary cooperation significantly improves the outcomes of children with Wilms tumor ${ }^{14-17}$. This collaboration contributed to the elucidation of the nature and clinical characteristics of various childhood malignant kidney tumors and enabled the completion of randomized trials of comparative treatment regimens. More recently, the Children's Oncology Group (COG) performed clinical trials ${ }^{18}$. The European group SIOP has conducted 6 clinical trials for Wilms tumor since $1971^{19-}$ 22. In 2001, several groups outside Europe joined the group, and the SIOP-2001 Wilms tumor study had patients enrolled from additional countries ${ }^{8}$.

The BWTSG has now changed its name to Brazilian Renal Tumors Group (BRTG) to include all renal tumors. The group has made efforts to improve participation through the development of a website (www. gbtr.com.br) to facilitate participation, case discussions, radiology and pathology review, improving diagnosis and treatment in this heterogeneous country. We have provided feedback to all hospitals regarding accrual rates of participation, and we believe physicians saw this as very positive feedback.

The present study has several limitations, mainly due to the analysis of secondary data collected at 105 different cancer treatment centers. We did not have information regarding the clinical epidemiologic aspects, such as stage distribution, histology, outcome, and treatment compliance, and we were unable to determine whether there was a selection bias in patient registration. One hospital provided additional information that they register only randomized cases (personal communication). Our results suggest that renal tumor cases are under-reported to the BWTSG in certain regions of Brasil, especially in the North. Even with its limitations, the present analysis of the accrual rates of participation by hospitals was valid, and we hope the findings will support improved participation accrual.

The questionnaire sent to all members of the SOBOPE served to highlight common problems among centers. From the results, we concluded that physicians understand the importance of trial participation, and that lack of time is the most important issue hindering registration. The major barrier to participation was lack of time to complete the forms. Physicians understand and agree that participation is important for better outcomes, improves knowledge, and has benefits for patients, multidisciplinary teams, and the hospital. Importantly, physicians did not report that they lack the financial support to participate, and they agree that participation is worth the required extra time. Notably, data from a Likert scale must be interpreted with caution, and further research is necessary.

We believe that the data from our present study will improve knowledge and participation, facilitating the exchange of information and research regarding renal tumors, not only around Brasil but globally, and will encourage collaboration at national and international levels. Strategies to increase participation have been suggested, and an online registration system is presently being implemented (www.gbtr.com.br).

\section{Acknowledgments}

We acknowledge all the efforts made by clinicians working at the childhood cancer centers from Brasil who enrolled and followed up patients in this study, and the patients and their families for their participation. The authors are grateful to all of the coordinators of the HBCR in Brasil that contributed to this work and to SOBOPE (Brazilian Pediatric Oncology Society) staff that sent the questionnaire and collaborated with the database of the BWTSG. LSV has a scholarship from CAPES/Ministério da Saúde; BDC has a scholar grant from CNPq 306291/2014-2 and Cientista do Nosso Estado (\#212989-2016) of the Fundação de Amparo à Pesquisa do Estado do Rio de Janeiro (FAPERJ)

\section{Authors disclosures and conflicts of interest}

All authors have no relationship to disclose

\section{Author contributions}

Lucian S. Viana: Data collection, analysis, and interpretation; final approval of the manuscript.

Rejane de Souza Reis, Marceli de Oliveira Santos, Neimar de Paula Silva, Nathalie V. Balmant, Paulo A. Faria, Beatriz de Camargo: Study conception and design; data analysis and interpretation; final approval of the manuscript. 


\section{RESUMO}

OBJETIVO: Crianças com tumores renais incluídas em ensaios clínicos apresentam melhora significativa na sobrevida. No entanto, o envolvimento desses pacientes em ensaios clínicos continua sendo um desafio no Brasil. Nosso objetivo neste estudo é descrever a taxa de aderência e adesão no Grupo Cooperativo Brasileiro para tratamento de Tumor de Wilms (GCBTTW) e identificar barreiras na participação ao protocolo.

MÉTODOS: Identificamos o número de casos de tumores renais diagnosticados em 105 registros hospitalares de câncer no período de 2001 a 2009. O número total desses casos foi então comparado ao número de casos de tumores renais registrados no GCBTTW provenientes das mesmas unidades hospitalares e durante o mesmo período. Os membros da Sociedade Brasileira de Oncologia Pediátrica foram convidados para completar um questionário com escala do tipo likert com o objetivo de conhecer suas opiniões sobre a importância e as dificuldades na participação em ensaios clínicos de grupos cooperativos.

RESULTADOS: A aderência de pacientes por hospital variou de 25\% a 76\% e foi maior na região Sul. A adesão da participação do hospital também variou de acordo com a região (20-31\%) e foi maior na região Sudeste. Com relação ao questionário referente à importância da participação em grupos cooperativos, as respostas mostraram concordância de mais de $75 \%$ em 10 das 13 afirmações.

CONCLUSÃO: Nossos resultados demonstraram uma baixa participação em grupos cooperativos no Brasil. Houve variações nas taxas de adesão e aderência de acordo com a região geográfica e unidade hospitalar, o que pode auxiliar em futuros esforços para a melhora dessas taxas. As respostas ao questionário demonstraram que os profissionais entendem a importância da participação em grupos cooperativos.

PALAVRAS-CHAVE: Neoplasias renais. Criança. Neoplasias. Brasil.

\section{REFERENCES}

1. Reaman G. Pediatric cancer research from past successes through collaboration to future transdisciplinary research. J Pediatr Oncol Nurs. 2004;21(3):123-7.

2. D'Angio GJ. Oncology seen through the prism of Wilms tumor. Med Pediatr Oncol. 1985;13(2):53-8.

3. Lennox EL, Stiller CA, Jones PH, Wilson LM. Nephroblastoma: treatment during 1970-3 and the effect on survival of inclusion in the first MRC trial. Br Med J. 1979;2(6190):567-9.

4. Deanburg A, Rodriguez-Galindo C, Joffe S. Clinical trials infrastructure as a quality improvement intervention in low- and middle-income countries. Am J Bioeth. 2016;16(6):3-11.

5. O'Leary M, Krailo M, Anderson JR, Reaman GH; Children's Oncology Group. Progress in childhood cancer: 50 years of research collaboration, a report from the Children's Oncology Group. Semin Oncol. 2008;35(5):484-93.

6. Camargo B, Franco EL. Single-dose versus fractionated-dose dactinomycin in the treatment of Wilms' tumor. Preliminary results of a clinical trial. The Brazilian Wilms' Tumor Study Group. Cancer. 1991;67(12):2990-6.

7. Kraker J, Voûte PA, Lemerle J, Tournade MF, Perry HJ. Preoperative chemotherapy in Wilms' tumour. Results of clinical trials and studies on nephroblastomas conducted by the International Society of Paediatric Oncology (SIOP). Prog Clin Biol Res. 1982;100:131-44.

8. Pritchard-Jones K, Bergeron C, Camargo B, van den Heuvel-Eibrink MM, Acha T, Godzinski J, et al; SIOP Renal Tumours Study Group. Omission of doxorubicin from the treatment of stage II-III, intermediate-risk Wilms' tumour (SIOP WT 2001): an open-label, non-inferiority, randomised controlled trial. Lancet. 2015;19(386(9999):1156-64.

9. Camargo B, Oliveira Ferreira JM, Souza Reis R, Ferman S, Oliveira Santos M, Pombo-de-Oliveira MS. Socioeconomic status and the incidence of non-central nervous system childhood embryonic tumours in Brasil. BMC Cancer. 2011;11:160.

10. Camargo B, Franco EL. A randomized clinical trial of single-dose versus fractionated-dose dactinomycin in the treatment of Wilms' tumor. Results after extended follow-up. Brazilian Wilms' Tumor Study Group. Cancer. 1994;73(12):3081-6.

11. Dome JS, Graf N, Geller JI, Fernandez CV, Mullen EA, Spreafico F, et al. Advances in Wilms tumor treatment and biology: progress through international collaboration. J Clin Oncol. 2015;33(27):2999-3007.
12. Ross JA, Severson RK, Pollock BH, Robison LL. Childhood cancer in the United States. A geographical analysis of cases from the Pediatric Cooperative Clinical Trials groups. Cancer. 1996;77(1):201-7.

13. Vujanić GM, Sandstedt B, Kelsey A, Sebire NJ. Central pathology review in multicenter trials and studies: lessons from the nephroblastoma trials. Cancer. 2009;115(9):1977-83.

14. D'Angio GJ, Evans A, Breslow N, Beckwith B, Bishop H, Farewell V, et al. The treatment of Wilms' tumor: results of the Second National Wilms' Tumor Study. Cancer. 1981;47(9):2302-11.

15. D'Angio G|, Breslow N, Beckwith |B, Evans A, Baum H, deLorimier A, et al. Treatment of Wilms' tumor. Results of the Third National Wilms' Tumor Study. Cancer. 1989;64(2):349-60.

16. Green DM, Breslow NE, Beckwith JB, Finklestein JZ, Grundy PE, Thomas $P R$, et al. A comparison between single-dose and divided-dose administration of dactinomycin and doxorubicin for patients with Wilms' tumor: a report from the National Wilms' Tumor Study Group. J Clin Oncol. 1998;16(1):237-45.

17. Beckwith JB, Palmer NF. Histopathology and prognosis of Wilms' tumor: results from the First National Wilms' Tumor Study. Cancer. 1978;41(5):1937-48.

18. Dome JS, Fernandez CV, Mullen EA, Kalapurakal JA, Geller JI, Huff V, et al; COG Renal Tumors Committee. Children's Oncology Group's 2013 blueprint for research: renal tumors. Pediatr Blood Cancer. 2013;60(6):994-1000.

19. Lemerle J, Voute PA, Tournade MF, Rodary C, Delemarre JF, Sarrazin D, et al. Effectiveness of preoperative chemotherapy in Wilms' tumor: results of an International Society of Paediatric Oncology (SIOP) clinical trial. J Clin Oncol. 1983;1(10):604-9.

20. Lemerle J, Voute PA, Tournade MF, Delemarre JF, Jereb B, Ahstrom L, et al. Preoperative versus postoperative radiotherapy, single versus multiple courses of actinomycin D, in the treatment of Wilms' tumor. Preliminary results of a controlled clinical trial conducted by the International Society of Paediatric Oncology (S.I.O.P.). Cancer. 1976;38(2):647-54.

21. Tournade MF, Com-Nougué $C$, Voûte PA, Lemerle |, de Kraker |, Delemarre JF, et al. Results of the Sixth International Society of Pediatric Oncology Wilms' Tumor Trial and Study: a risk-adapted therapeutic approach in Wilms' tumor. J Clin Oncol. 1993;11(6):1014-23.

22. Graf N, Tournade MF, de Kraker |. The role of preoperative chemotherapy in the management of Wilms' tumor. The SIOP studies. International Society of Pediatric Oncology. Urol Clin North Am. 2000;27(3):443-54. 